\title{
Efecto de Temperatura, pH, Concentración de Sustrato y Tipo de Enzima en la Hidrólisis Enzimática de Vísceras de Tilapia Roja (Oreochromis spp.)
}

\author{
Andrea J. Baez-Suarez, Nelly Ospina-de-Barreneche y José E. Zapata-Montoya \\ Universidad de Antioquia, Facultad de Ciencias Farmacéuticas y Alimentarias, Grupo de Nutrición y \\ Tecnología de Alimentos, Calle 67 No. 53-103, Medellín, Colombia. \\ (e-mail: joha.baez@yahoo.es; nospina400@yahoo.es; jedgar_4@yahoo.es)
}

Recibido Nov. 26, 2015; Aceptado Feb. 8, 2016; Versión final Mar. 26, 2016, Publicado Dic. 2016

\begin{abstract}
Resumen
Se prepararon hidrolizados de proteína a partir de vísceras de Tilapia roja (Oreochromis spp.), una importante especie de pescado de gran producción en Colombia. En la hidrólisis se evaluaron tres enzimas diferentes (Alcalase, Neutrase y Flavourzyme) para establecer con cuál de ellas se obtendría el mayor grado de hidrólisis $(\mathrm{GH})$. Se utilizó el método del pH-stat y en cada enzima se aplicó un diseño factorial $2^{2}$ para evaluar el efecto de la temperatura y el pH, sobre el GH. Se alcanzaron valores máximos de GH de 10.9\%. para Alcalasa, y $3.9 \%$ para Neutrasa y Flavourzyme. Posteriormente se realizó un análisis de superficie de respuesta $3^{2}$ para la hidrolisis con Alcalase. Los resultados mostraron que el $\mathrm{GH}$ fue maximizado bajo las siguientes condiciones: $\mathrm{pH}=9.5$ y $\mathrm{T}=53.45^{\circ} \mathrm{C}$ manteniendo constante la concentración inicial de sustrato, concentración de enzima y tiempo de reacción. Finalmente se evaluó el efecto del sustrato variando la concentración de proteína entre $12.5 \mathrm{~g} / \mathrm{L}, 21.25 \mathrm{~g} / \mathrm{L}, 29.5 \mathrm{~g} / \mathrm{L}$ y $37.5 \mathrm{~g} / \mathrm{L}$ y determinando las constantes cinéticas de Michaelis-Menten.
\end{abstract}

\section{Effect of Temperature, $\mathrm{pH}$, Substrate Concentration and type of Enzyme on the Enzymatic Hydrolysis of Viscera of Red Tilapia (Oreochromis spp.)}

\begin{abstract}
Protein hydrolysates were prepared from viscera of red tilapia (Oreochromis spp.), an important fish species of great production in Colombia. Hydrolysis with three different enzymes (Alcalase, Flavourzyme and Neutrase) were evaluated to establish which of them deliver the highest degree of hydrolysis (DH) using the $\mathrm{pH}$-stat method. On each enzyme a $2^{2}$ factorial design was applied to evaluate the effect of temperature and $\mathrm{pH}$ on the $\mathrm{DH}$. Maximum DH values of $10.9 \%$ for Alcalase and $3.9 \%$ for Flavourzyme and Neutrase were obtained. Subsequently, a response surface $3^{2}$ analysis for the hydrolysis with Alcalase was performed. The results showed that the $\mathrm{DH}$ is maximized when working at $\mathrm{pH}=9.5$ and $\mathrm{T}=53.45^{\circ} \mathrm{C}$ keeping constant the initial substrate concentration, enzyme concentration and reaction time. Finally the effect of substrate was evaluated varying protein concentration between $12.5 \mathrm{~g} / \mathrm{L}, 21.25 \mathrm{~g} / \mathrm{L}, 29.5 \mathrm{~g} / \mathrm{L}$ and $37.5 \mathrm{~g} / \mathrm{L}$. Furthermore, the kinetic constants of Michaelis-Menten were evaluated.
\end{abstract}

Keywords: tilapia viscera; fish protein hydrolysates; degree of hydrolysis; factorial design 


\section{INTRODUCCIÓN}

La industria del pescado es una fuente de ingresos muy importante para la mayoría de países en el mundo. Se estima que en todo el globo, mil millones de personas dependen de la producción, procesamiento y comercialización de la pesca para su sustento, siendo la proteína del pescado una fuente esencial de alimentos para humanos, especialmente en los países en desarrollo (Dekkers et al., 2011). Asociado a ello, en la industria de procesamiento de pescado el $60 \%$ de la producción corresponde a los residuos y solo el $40 \%$ se destina al consumo humano (Arvanitoyannis, 2008; Dekkers et al., 2011; Saadi et al., 2015). Los residuos se componen principalmente de restos de fileteo (15-20\%), piel y aletas (1-3\%), huesos (9-15\%), cabezas (9-12\%), vísceras (12-18\%) y escamas (5\%) (Martínez et al., 2015). Los cuales, a pesar de ser importantes fuentes de proteínas, la mayoría de las veces son descartados sin ningún intento de recuperación o destinados a alimentación animal, harina de pescado o fertilizantes (Ovissipour et al., 2009; Hsu, 2010; Chalamaiah et al., 2012; Deraz., 2014).

Durante los últimos años han sido propuestos diferentes métodos para el tratamiento de los residuos sólidos procedentes de la pesca, entre los cuales se cuentan hidrólisis, biorremediación, ensilaje y filtración (Arvanitoyannis., 2008). Los primeros procesos utilizados basados en hidrolisis químicas y extracción con solventes orgánicos dieron malos resultados en términos de calidad nutricional de las proteínas y conservación de los aminoácidos (Shahidi et al., 1999). En la última década se han logrado progresos con la aplicación de procesos enzimáticos para producir hidrolizados proteicos a partir de residuos de pescado con la utilización de enzimas exógenas comerciales para que el proceso sea más controlable y reproducible (Dong et al.,2005; Duan et al., 2010; Chalamaiah et al., 2012; Shahidi y Ambigaipalan; 2015). En consecuencia, se han usado en hidrolisis enzimática de subproductos de pescado enzimas tales como Alcalasa, papaína, pepsina, tripsina, pancreatina, Flavourzyme, pronasa, Neutrasa, protamex y termolisina (Ren et al., 2008; Hsu, 2010).

Los hidrolizados de proteína de subproductos acuícolas, además de tener un excelente equilibrio de aminoácidos, una buena digestibilidad y una rápida absorción; poseen ciertas propiedades tecnofuncionales (He et al., 2013), ácidos grasos omega-3 (Ghaly et al., 2013; Silva et al., 2014) y son una de las principales fuentes de péptidos bioactivos (Valencia et al., 2014; Chalamaiah et al., 2012; Liu et al., 2014). Los cuales dependiendo de su composición, secuencia y número de aminoácidos (generalmente entre 2 20), pueden poseer actividades biológicas, como: antihipertensiva, antioxidante, inmunomoduladora, antitrombótica, anticancerígena, entre otras (Lee et al., 2010; Picot et al., 2010; Wang et al., 2013; Deraz, 2014; Shahidi y Ambigaipalan, 2015). Diferentes investigaciones, han establecido la relación existente entre la actividad biológica de los péptidos y su peso molecular (Bourseau et al., 2009; Picot et al., 2010; Saidi et al., 2013; Wang et al., 2013; Liu et al., 2014). En particular, las fracciones de péptidos con pesos moleculares entre 1-4kDa, serían los más interesantes para usos nutricionales y/o farmacéuticos (Saidi et al., 2014; de Castro y Sato, 2015; Opheim et al., 2015). Por lo tanto, obtener hidrolizados con altos grados de hidrólisis (GH), incrementa la posibilidad de obtener péptidos bioactivos (Gómez et al., 2013). El objetivo del presente estudio fue seleccionar la enzima (Alcalasa, Flavourzyme y Neutrase) que exhibiera un mayor GH durante la hidrólisis de la proteína presente en las vísceras de tilapia roja (Oreochromis spp.). Asimismo se establecieron las condiciones de hidrólisis que maximizaran el $\mathrm{GH}$ en función del pH y la temperatura del proceso y se evaluó el efecto del sustrato sobre la velocidad de la reacción hidrolítica.

\section{MATERIALES Y MÉTODOS}

Esta sección se presenta en varias subsecciones partiendo por I descripción general de los materiales. Luego se describen las enzimas utilizadas, se explica el sistema de reacción usado, para luego describir como se realiza el análisis proximal del sustrato y el diseño experimental. Finalmente, se explica el proceso de hidrólisis enzimática, la determinación del grado de hidrolisis, el efecto del tiempo de hidrólisis sobre el GH y el efecto de la concentración de sustrato sobre el GH

\section{Materiales}

El sustrato usado en este estudio fue vísceras de tilapia roja, suministradas por la asociación de piscicultores de San Carlos (ASOPISAN), Antioquia. Los residuos se transportaron refrigerados hasta el laboratorio del grupo de investigación en Nutrición y Tecnología de Alimentos de la Universidad de Antioquia, donde fueron almacenados a $-20^{\circ} \mathrm{C}$ hasta su uso. Todos los reactivos usados en el estudio fueron de grado analítico.

\section{Enzimas}

Todas las enzimas utilizadas fueron de grado alimenticio. Se usó Alcalasa 2,4L (2,4 AU-A/g), una enzima proteolítica producida por fermentación sumergida de una cepa seleccionada de Bacillus licheniformis, con 
temperaturas de trabajo entre $55^{\circ} \mathrm{C}$ y $70^{\circ} \mathrm{C}$ y pH entre 6,5 y 8,5, dependiendo del tipo de sustrato (Belén Camacho et al., 2007). Neutrasa 1,5MG (1,5 AU-NH/g), es una enzima proteolítica producida por fermentación sumergida de una cepa seleccionada de Bacillus subtilis, con temperaturas de trabajo entre $45^{\circ} \mathrm{C}-55^{\circ} \mathrm{C}$ y pH 5,5-7,5 (Slizyte et al., 2005). Flavourzyme 500MG (500 LAPU/g), es un complejo de proteasa fúngica y peptidasa producido por fermentación sumergida de una cepa seleccionada de Aspergillus Oryzae, contiene tanto actividades de endoproteasa como de exopeptidasa, su pH de trabajo está entre $5,0-8,0$, y su temperatura entre $50-60^{\circ} \mathrm{C}$ (Dekkers et al., 2011).

\section{Sistema de reacción}

Se usó un reactor de vidrio de $1 \mathrm{~L}$ de capacidad con camisa de circulación de agua para regular la temperatura, al cual se llevaron $400 \mathrm{~g}$ de agua y $400 \mathrm{~g}$ de vísceras. El control de $\mathrm{pH}$ se realizó con un ecotrodo con diafragma esmerilado fijo (temperatura entre $0-80{ }^{\circ} \mathrm{C}$ ), conectado a un titulador automático Titrando 842 (Metrohm, Suiza), operado con el software tiamo 1.2.1. El sistema de reacción se mantuvo en agitación constante.

\section{Análisis proximal del sustrato}

El contenido de humedad se determinó según la norma AOAC 930.15 (AOAC, 1990), el extracto etéreo según la norma AOAC 960.39 (AOAC, 1990), las cenizas según la AOAC 920.153 (AOAC, 1990) y la proteína según la AOAC 954.01(AOAC, 1990).

\section{Diseño experimental}

Se usaron diseños factoriales $2^{2}$ para evaluar el comportamiento de cada enzima en un rango de $\mathrm{pH}$ y temperatura definidos con base en la literatura (Kechaou, et al., 2009) y en ensayos preliminares. Los niveles de los factores utilizados se presentan en la Tabla 1 y en la Tabla 2, las corridas de los diseños experimentales con los valores del GH para cada corrida.

Tabla 1: Niveles de los factores para los Diseños factoriales $2^{2}$ en cada enzima.

\begin{tabular}{|l|c|c|}
\hline Enzima & $\mathrm{T}\left({ }^{\circ} \mathrm{C}\right)$ & $\mathrm{pH}$ \\
\hline Alcalasa 2.4L & $45-65$ & $7,5-9,5$ \\
\hline Neutrasa 1.5MG & $40-60$ & $6,0-8,0$ \\
\hline Flavourzyme 500MG & $40-60$ & $6,0-8,0$ \\
\hline
\end{tabular}

Tabla 2: Diseño factorial $2^{2}$ y GH obtenidos para cada enzima

\begin{tabular}{|c|l|c|c|c|}
\hline Exp. & Enzima & $\mathrm{T}\left({ }^{\circ} \mathrm{C}\right)$ & $\mathrm{pH}$ & $\mathrm{GH}(\%)$ \\
\hline 1 & & 45 & 7,5 & 9,0 \\
2 & Alcalasa 2.4L & 65 & 7,5 & 10,9 \\
3 & & 45 & 9,5 & 10,4 \\
4 & & 65 & 9,5 & 7,0 \\
\hline 1 & & 40 & 6,0 & 2,3 \\
2 & & 60 & 6,0 & 1,9 \\
3 & \multirow{2}{*}{ Neutrasa 1.5MG } & 40 & 8,0 & 3,4 \\
4 & & 60 & 8,0 & 3,9 \\
\hline 1 & & 40 & 6,0 & 3,9 \\
2 & \multirow{2}{*}{ Flavourzyme } & 60 & 6,0 & 1,5 \\
3 & 500MG & 40 & 8,0 & 2,2 \\
4 & & 60 & 8,0 & 2,2 \\
\hline
\end{tabular}

A partir de los resultados de los diseños experimentales factoriales $2^{2}$, se eligió la enzima que entrega el mayor GH, y con ella se planteó un nuevo diseño factorial $3^{2}$ (Tabla 3 ). El análisis de los datos se realizó por el método de superficie de respuesta empleando el software Desing Expert 8.0.7.1 (Stat-Ease Inc, USA).

\section{Hidrólisis enzimática}

Las vísceras de Tilapia se prensaron para reducir su contenido de aceite y se mezclaron con agua destilada en una relación 1:1 $(\mathrm{m} / \mathrm{V})$. La cantidad de agua añadida es una importante variable en el proceso de hidrólisis, dado que un bajo valor de agua añadida, no sólo puede disminuir la hidrólisis debido a la falta de acceso de la enzima a los sustratos, sino también la alta viscosidad de la mezcla puede conducir a una menor recuperación de las proteínas hidrolizadas (Shetty et al.,2006). Las vísceras previamente tratadas contenían $8,10 \%$ de proteínas y fueron hidrolizadas con $1 \mathrm{~g}$ enzima por cada $100 \mathrm{~g}$ de vísceras, lo que 
corresponde a una concentración de sustrato de $40,5 \mathrm{~g} / \mathrm{L}$ y una relación enzima/sustrato de 0,1 . Valores que se definieron con base en la literatura (Slizyte et al., 2005; Kechaou et al., 2009; He et al., 2013). El pH y la temperatura en el reactor se ajustaron con base en el diseño experimental (tabla 2). Cada ensayo tuvo una duración total de 6 horas, tomando registros del volumen de base gastado y calculando el GH, cada 5 min. Al finalizar el proceso de hidrólisis, se inactivó la enzima calentando el sistema a $95^{\circ} \mathrm{C}$ por $15 \mathrm{~min}$.

Caracterización parcial del hidrolizado

A los hidrolizados obtenidos con las condiciones óptimas de pH y temperatura, se les tomó muestras a las 6 horas de reacción, después de la inactivación de la enzima $\left(95^{\circ} \mathrm{C}, 15 \mathrm{~min}\right)$, esta solución se dejó a temperatura ambiente durante 20 minutos y seguidamente se centrifugo para separar la fracción rica en proteínas hidrolizadas, de las partes insolubles como la grasa, los residuos de hueso, tejido conectivo y la proteína no hidrolizada.

\section{Determinación del grado de hidrolisis}

La reacción a pH alcalino se observó para la determinación del GH, expresado como la relación entre el número de enlaces peptídicos hidrolizados $(h)$ y el número de enlaces peptídicos totales en la proteína nativa por unidad de peso ( $h t$ ) (Adler-Nissen, 1986). El método empleado para la determinación del GH fue el de valoración del protón o método del pH-estato. El cual consiste en mantener constante el pH del medio de reacción con adición de una solución básica (hidróxido de sodio $2.0 \mathrm{~N}$ ), pues a medida que la hidrólisis avanza en medio alcalino, el grupo carboxilo terminal se disocia por completo y los protones formados se reparten de acuerdo con el equilibrio de protonación de los grupos a-amino liberados. La base agregada para mantener constante el pH neutraliza únicamente los protones que son sustituidos por el catión de la base (Guadix et al., 2002).

En la hidrólisis de un enlace amino a pH alcalino, se siguen las siguientes etapas (Guadix et al., 2002):

$-\mathrm{CHR}^{\prime}-\mathrm{CO}-\mathrm{NH}-\mathrm{CHR}^{\prime \prime}-+\mathrm{H}_{2} \mathrm{O} \stackrel{\text { enzima }}{\longrightarrow}-\mathrm{CHR}^{\prime}-\mathrm{COOH}+\mathrm{NH}_{2}-\mathrm{CHR}^{\prime \prime}$

El grupo carboxilo terminal se disocia por completo:

$-\mathrm{CHR}^{\prime}-\mathrm{COOH}+\mathrm{NH}_{2}-\mathrm{CHR}^{\prime \prime} \rightarrow-\mathrm{CHR}^{\prime}-\mathrm{COO}^{-}+\mathrm{NH}_{3}^{+}-\mathrm{CHR}^{\prime \prime}$

La base agregada neutraliza los protones:

$\rightarrow \mathrm{NH}_{3}^{+}-\mathrm{CHR}^{\prime \prime}+\mathrm{OH}^{-} \leftrightarrow \mathrm{NH}_{2}-\mathrm{CHR}^{\prime \prime}+\mathrm{H}_{2} \mathrm{O}$

Esta técnica permite correlacionar el $\mathrm{GH}$ con la cantidad de base añadida para mantener constante el pH (Adler-Nissen, 1986), luego este consumo de base puede relacionarse con el GH según las ecuaciones (13).

$\% G H=\frac{V_{B *} N_{B}}{M_{P}} \frac{1}{\alpha} \frac{1}{h_{t o t}} \times 100$

$\alpha=\frac{10^{p H-p K}}{1+10^{p H-p K}}$

$\mathrm{pk}=7,8+\frac{(298-\mathrm{T})}{298 * \mathrm{~T}} 2400$

Donde $\mathrm{Vb}$ es el volumen consumido de base en $\mathrm{L}, N_{B}$ es la normalidad de la base (Eq-g/L), Mp es Masa de la proteína en $\mathrm{Kg}$, htot es el número total de enlaces peptídicos en la muestra (eq/g proteína). Para las proteínas del pescado su valor es 8,6 eq/kg (Adler-Nissen, 1986; Balti et al., 2015; Kechaou et al., 2009). a en la ecuación (2) es el grado de disociación promedio de los grupos $\alpha-\mathrm{NH}_{2}$ liberados en la reacción, el cual depende del pK, que a su vez es función de la temperatura, en la forma que se aprecia en la ecuación (3) (Valencia et al., 2014).

\section{Efecto del tiempo de hidrólisis sobre el GH}

Bajo las condiciones de máximo $\mathrm{GH}$ definidas en el diseño experimental $3^{2}$, se evaluó el efecto del tiempo sobre el GH. Para esto se tomaron datos de GH en función del tiempo, durante $6 \mathrm{~h}$, los cuales se ajustaron utilizando un programa disponible en línea, Zunzun (2012) tomando como criterio de selección del modelo el $R^{2}$ y la raíz cuadrada del error medio (RCEM). 


\section{Efecto de la concentración de sustrato sobre el GH}

Las vísceras de Tilapia roja (Oreochromis sp.), se diluyeron en agua para obtener concentraciones de proteína de 12,5, 21,5, 29,5 y 37,5 en g/L. En cada una de estas condiciones se desarrollaron corridas experimentales a $53,45^{\circ} \mathrm{C}, \mathrm{pH} 9,5$ y relación enzima/sustrato 0,2 , para evaluar el efecto que la concentración de sustrato tiene sobre la velocidad de la reacción, la cual está dada por la ecuación (4) (Qi y $\mathrm{He}, 2006)$.

$$
\mathrm{r}=\mathrm{S}_{\mathrm{O}} \frac{\mathrm{d}(\mathrm{GH})}{\mathrm{dt}}
$$

Donde $r$ denota la velocidad inicial en la reacción $\left(g / L^{*} \min \right), S_{0}$ la concentración inicial del sustrato $(g / L)$ y $t$ el tiempo ( $\mathrm{min})$.

Para la determinación de las constantes de Michaelis-Mentes ( $K_{M}$ y $\left.r_{\max }\right)$, se utilizó la aproximación de doble reciproco de Hannes-Woolf que se presenta en la ecuación (5) (Ritchie y Prvan, 1996).

$\frac{S}{r}=\frac{1}{r_{\max }} * S+\frac{K_{m}}{r_{\max }}$

\section{RESULTADOS Y DISCUSION}

Los resultados son preentados en siete subsecciones: (i) Análisis químico proximal de las vísceras, (ii) Selección de la enzima con mayor $\mathrm{GH}$, (iii) Efecto del $\mathrm{pH}$ y la temperatura sobre el $\mathrm{GH}$ en la hidrólisis enzimática con Alcalasa, (iv) Maximización del GH del Diseño $3^{2}$, (v) Efecto del tiempo sobre el GH en la hidrolisis enzimática vísceras de tilapia roja, (vi) Efecto de la concentración de sustrato sobre el GH, en la hidrolisis enzimática de vísceras de tilapia roja, y (vii) Composición química proximal del hidrolizado

\section{Análisis químico proximal de las vísceras}

La composición química proximal de las vísceras evaluadas fue humedad $62,07 \%$, el mayor componente de interés nutricional la proteína cruda, fue $8,10 \%$, seguido del contenido graso $27,63 \%$ y ceniza total 1,80\%. Bhaskar y Mahendrakar (2008) señalaron un contenido de humedad superior $(76,25 \%)$ para vísceras de Catla Catla pero valores similares de proteína $(8,52 \%)$ y valores inferiores de grasa $(12,46 \%)$, así como un contenido superior de ceniza $(2,50 \%)$. Las diferencias entre las composiciones de las vísceras de las dos especies se deben a la influencia de factores tales como el sexo, la edad, la zona de captura y la época del año (Sikorski, 1994; Astiasarán, 2000). La baja proporción de ceniza se debe a están desprovista de espinas y escamas (Rodríguez et al., 2001). Por otro lado el pH inicial de las vísceras fue de 5,84 el cual está dentro del rango usual, que generalmente varía entre 5,85 y 6,25 en vísceras de pescado (Bhaskar y Mahendrakar, 2008).

\section{Selección de la enzima con mayor $\mathrm{GH}$}

En la Tabla 2 se muestran los resultados experimentales obtenidos para el GH de cada enzima en los diferentes $\mathrm{pH}$ y temperatura. Se evidencia que Alcalasa 2,4L presenta los valores más altos para GHs comparados con Flavourzyme y Neutrasa para todas las combinaciones de $\mathrm{pH}$ y temperaturas evaluadas, lo cual puede deberse a que las proteasas alcalinas, entre las que se encuentra la Alcalasa 2,4L, muestran actividades mayores que las proteasas neutras, como Flavourzyme y Neutrasa, cuando actúan sobre proteínas de pescado (Dumay et al., 2006; Klompong et al., 2007). Esto tiene importancia si se considera que el mayor grado de hidrólisis en estos sustratos, puede estar asociado al incremento de los niveles de amino ácidos esenciales, por ende del valor nutricional de los productos alimenticios derivados de los mismos (Kechaou, et al., 2009). Adicionalmente, altos grados de hidrólisis de subproductos pesqueros se han relacionado con mayor capacidad de captura de radicales y mayor capacidad reductora de los hidrolizados (Batista, et al., 2010; Gómez et al., 2013). En general se ha documentado ampliamente la relación existente entre bajos pesos moleculares de péptidos y actividad biológica (Bourseau et al., 2009, Picot et al., 2010; Saidi et al., 2013; Wang et al., 2013; Liu et al., 2014). Las aplicaciones más interesantes en este aspecto se han encontrado en péptidos con pesos moleculares entre 1 - 4kDa (Saidi et al., 2014; De Castro y Sato, 2015; Opheim et al., 2015).

\section{Efecto del pH y la temperatura sobre el GH en la hidrólisis enzimática con Alcalasa}

Con base en los resultados discutidos en el apartado anterior, se escoge la Alcalasa 2,4L., como la enzima a trabajar en la hidrólisis enzimática de vísceras de tilapia roja (Oreochromis spp.). Con dicha enzima, se plantea evaluar el efecto que tienen el $\mathrm{pH}$ y la temperatura sobre el $\mathrm{GH}$, por medio de un diseño 
experimental factorial $3^{2}$. En la tabla 3 se muestran las corridas experimentales de este diseño, con los valores del GH para cada una respectivamente. Estos datos se emplearon en el ajuste de un modelo polinomial de segundo orden, cuyos coeficientes fueron calculados por regresión múltiple utilizando el software Desing Expert 8.0.7.1 (Stat-Ease Inc, USA).

Tabla 3: Diseño factorial completo $3^{2}$ y GHs obtenidos con Alcalasa 2,4L.

\begin{tabular}{|c|c|c|c|}
\hline Exp & $\begin{array}{c}\text { Temperatura } \\
(\stackrel{\circ}{ } \text { C) }\end{array}$ & $\mathrm{pH}$ & \multirow{2}{*}{$\mathrm{GH}(\%)$} \\
\cline { 2 - 3 } & $\mathrm{A}$ & $\mathrm{B}$ & \\
\hline 1 & 45 & 7,5 & 9,0 \\
\hline 2 & 55 & 8,5 & 9,9 \\
\hline 3 & 45 & 8,5 & 9,4 \\
\hline 4 & 65 & 7,5 & 10,9 \\
\hline 5 & 55 & 8,5 & 8,4 \\
\hline 6 & 55 & 8,5 & 10,4 \\
\hline 7 & 65 & 9,5 & 7,0 \\
\hline 8 & 65 & 8,5 & 11,5 \\
\hline 9 & 55 & 7,5 & 7,7 \\
\hline 10 & 55 & 9,5 & 13,8 \\
\hline 11 & 45 & 9,5 & 10,4 \\
\hline 12 & 55 & 8,5 & 9,6 \\
\hline 13 & 55 & 8,5 & 9,8 \\
\hline
\end{tabular}

En la Tabla 4, se presenta el análisis de varianza (ANOVA) para el diseño factorial $3^{2}$, y en la ecuación 6 , el modelo ajustado con los términos significativos. En ella se observa la significancia del modelo, y la no significancia de la falta de ajuste, lo cual indica un buen ajuste de los datos al modelo. A pesar de no contar con un $\mathrm{R}^{2}$ muy alto, este modelo nos permite observar los efectos más importantes de los factores, así como el signo que estos efectos tienen sobre la respuesta. Se observa que la variable $T$ en su forma lineal, junto con la interacción entre $\mathrm{pH}$ y $\mathrm{T}$, no influyen significativamente en el $\mathrm{GH}$, pero por otro lado, el pH en su forma lineal $(P=0,0057)$ y $T$ en forma cuadrática $(0,0464)$, tienen un efecto significativo, así como la interacción entre $\mathrm{pH} \mathrm{y}^{2}(0,0062)$, lo cual pone de manifiesto la interacción compleja de estos dos factores en este proceso. A pesar de que la temperatura no tiene significancia en su término lineal, este término no se puede eliminar del modelo para no perder la jerarquía del mismo. El efecto significativo de $T$ en su forma cuadrática $(\mathrm{P}=0,0464)$, geométricamente implica una curvatura del comportamiento de la función. La

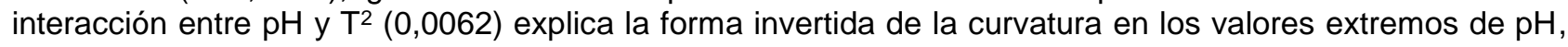
como se observa en la figura 1.

Tabla 4: Análisis de regresión Valor-p, nivel de significancia

\begin{tabular}{|c|c|c|c|c|c|}
\hline Factor & Suma de cuadrados & Grados de libertad & Cuadrado medio & Valor $F$ & Valor $P$ \\
\hline Modelo & 27,44 & 5 & 5,49 & 4,56 & 0,0361 \\
\hline $\mathrm{T}$ & 0,06 & 1 & 0,06 & 0,05 & 0,8297 \\
\hline $\mathrm{pH}$ & 18,61 & 1 & 18,61 & 15,45 & 0,0057 \\
\hline $\mathrm{T} \times \mathrm{pH}$ & 7,02 & 1 & 7,02 & 5,83 & 0,7026 \\
\hline $\mathrm{T}^{2}$ & 0,19 & 1 & 0,19 & 0,16 & 0,0464 \\
\hline $\mathrm{T}^{2} \mathrm{XPh}$ & 18,01 & 1 & 18,01 & 14,96 & 0,0062 \\
\hline Residual & 8.43 & 7 & 1,20 & & \\
\hline $\begin{array}{c}\text { Falta de } \\
\text { ajustes }\end{array}$ & 6,22 & 3 & 2,07 & 3,76 & 0,1169 \\
\hline Error puro & 2,21 & 4 & 0,55 & & \\
\hline $\mathrm{R}^{2}$ & 35,87 & 12 & & & \\
\hline
\end{tabular}

$$
\mathrm{GH}=859.11-32.96 * \mathrm{~T}-100.83 * \mathrm{pH}+0.31 * \mathrm{~T}^{2}+3.91 * \mathrm{~T} * \mathrm{pH}-0.037 * \mathrm{~T}^{2} * \mathrm{pH}
$$

En la figura 1, se muestra la superficie de respuesta para ilustrar los efectos principales e interactivos de los factores sobre el GH a una concentración de enzima del 1\%, concentración de sustrato en relación 1:1(w/v) y 6 horas de reacción. Los datos experimentales, ponen en evidencia el efecto de la temperatura de 
reacción sobre el $\mathrm{GH}$, que según el análisis de varianza es de segundo orden. Aquí se observa que a pH de 9,5 , se registra un aumento del $\mathrm{GH}$ con el aumento de la temperatura hasta las regiones cercanas al punto central del intervalo de evaluación (alrededor de $55^{\circ} \mathrm{C}$ ), por encima de este punto de temperatura el GH se ve disminuido. Lo cual puede deberse a que teóricamente, un incremento de temperatura aumenta la energía cinética a las moléculas, pero debido a la naturaleza proteica de las enzimas su estructura terciaria se ve comprometida cuando se alcanzan elevadas temperaturas, lo que conduce a la pérdida de actividad catalítica (Pérez-Gálvez et al., 2011), que se traduce en una disminución del GH cuando se trabaja por encima de un cierto límite de temperatura (Prieto, 2008). En cuanto al pH, se conoce que cambios en su nivel afecta tanto al sustrato como a la enzima, porque cambia la distribución de cargas y la conformación de las proteínas (Roslan et al., 2014). Además, el pH pueden influenciar la disociación de grupos activos de la enzima, afectando la dinámica de asociación de ésta con el sustrato (Shi et al., 2005).

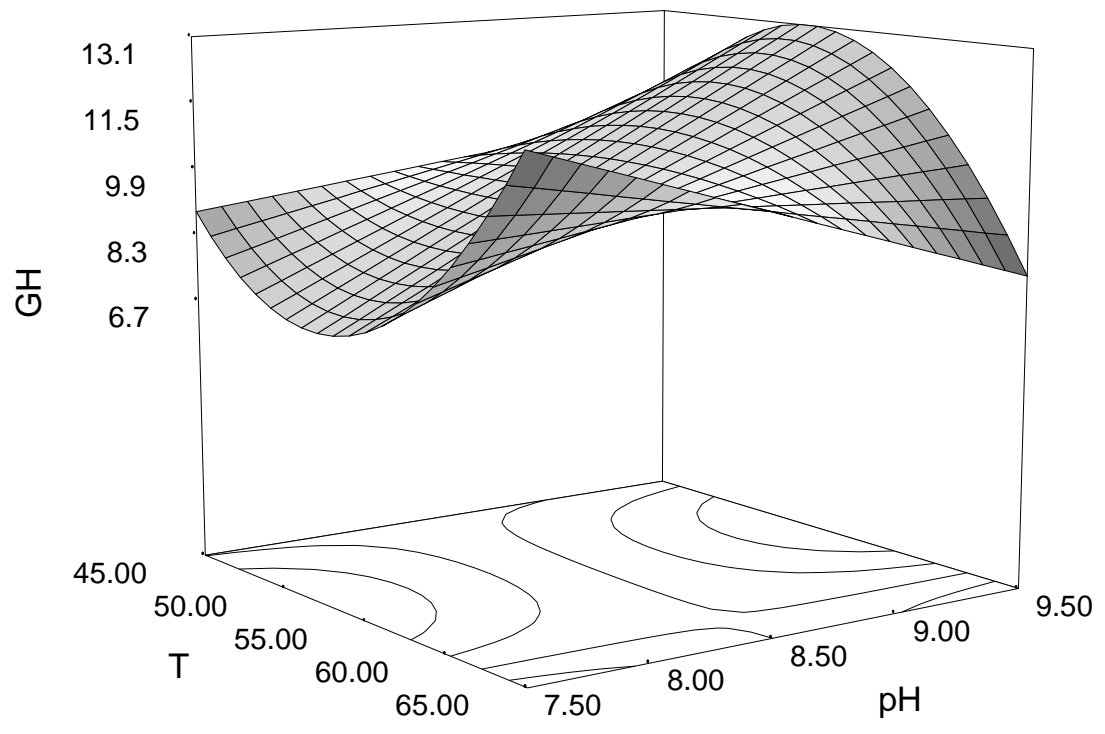

Fig. 1: Superficie de respuesta para el GH en función de $\mathrm{T}$ y pH durante la hidrólisis enzimática de vísceras de Tilapia con Alcalasa 2,4L.

\section{Maximización del GH del Diseño $3^{2}$}

El modelo que se presenta en la ecuación 6 , se sometió a un proceso de maximización del GH, en función de $\mathrm{pH}$ y temperatura, cuyos resultados se presentan en la tabla 4. Para comprobar la validez de los resultados de la maximización, se llevaron a cabo tres corridas experimentales de hidrólisis bajo las condiciones óptimas establecidas ( $\mathrm{pH}=9,5$ y $\mathrm{T}=53,45^{\circ} \mathrm{C}$ ), los datos experimentales obtenidos se muestran en la Tabla 4. Estos valores de GH concuerdan con los de Gbogouri et al. (2004) quienes obtuvieron GH entre $11,5-17,3 \%$, trabajando con temperaturas entre $49-61^{\circ} \mathrm{C}$, en un proceso de optimización con superficies de respuesta, en la hidrólisis de cabezas de salmón utilizando Alcalasa. Además, están por encima de los resultados de Souissi et al. (2007) quienes describieron hidrolisis de proteínas con GH de 6,$62 ; 9,31$ y $10,16 \%$ a partir de cabezas y vísceras de sardinella (Sardinella aurita) por tratamiento con Alcalasa. La diferencia con este último trabajo, puede deberse a que ellos no establecieron las condiciones óptimas de $\mathrm{pH}$ y temperatura, sino que trabajaron a $\mathrm{pH} 8$ y temperatura de $50^{\circ} \mathrm{C}$.

Tabla 5: GH teórico y experimental a T y pH óptimos.

\begin{tabular}{|c|c|c|c|}
\hline \multicolumn{2}{|c|}{ Factores } & GH Pred. & GH Exp. \\
\cline { 1 - 2 } $\mathrm{T}\left({ }^{\circ} \mathrm{C}\right)$ & 53,45 & \multirow{2}{*}{13,0413} & $12,03 \pm 0.65$ \\
\cline { 1 - 2 } $\mathrm{pH}$ & 9,50 & & \\
\hline
\end{tabular}

Los valores de temperatura obtenidos en la maximización corresponden con la mayoría de los estudios de optimización de hidrólisis de proteínas de pescado usando Alcalasa, los cuales han reportado temperaturas óptimas de $50^{\circ} \mathrm{C}$ (Roslan et al., 2014), $55^{\circ} \mathrm{C}$ (See et al. 2011) y $60^{\circ} \mathrm{C}$ (Amiza et al. 2011). En cuanto al pH, se debe considerar que el rango reportado para Alcalasa está entre 6-10, siendo el valor óptimo dependiente del sustrato usado (Bhaskar et al., 2008; Amiza et al., 2011; See et al., 2011). 


\section{Efecto del tiempo sobre el GH en la hidrolisis enzimática vísceras de tilapia roja}

Los datos obtenidos a las condiciones óptimas definidas por el Diseño Experimental $3^{2}$ fueron seguidos durante 6 horas para establecer el modelo que ajustara el comportamiento del GH en función del tiempo (figura 2). Con los datos experimentales se llevó a cabo un ajuste empleando el software en línea Zunzun (2012); tomando como criterio de selección del modelo el $R^{2}$ y la raíz cuadrada del error medio (RCEM). Se evaluaron diferentes familias de ecuaciones, entre las que emergió la familia exponencial como la más recomendada. Entre las ecuaciones exponenciales evaluadas se seleccionó la Exponencial Doble Asintótica, que se muestra en la ecuación 7, la cual tiene como parámetros las constantes a, b, c y d, que se presentan en la tabla 6 , en la que aparecen también el $R^{2}$ y la RCEM.

$G H=a *(1.0-\exp (\mathrm{b} * \mathrm{t}))+\mathrm{b} *(1.0-\exp (\mathrm{d} * \mathrm{t}))$

Tabla 6: Parámetros de la ecuación 7.

\begin{tabular}{|c|c|}
\hline Parámetro & Valor \\
\hline$A$ & 63,18 \\
\hline$B$ & $-0,02189$ \\
\hline$C$ & 4,340 \\
\hline$D$ & $-3,608$ \\
\hline$R^{2}$ & 0,9973 \\
\hline$R^{2}$ ajustado & 0,9963 \\
\hline RCEM & 0,1680 \\
\hline
\end{tabular}

En la figura 2, se observa el comportamiento de los valores predichos por el modelo (Ec. 7), en contraste con los datos experimentales, lo cual constata el excelente ajusté que existe entre los datos experimentales y el modelo, que ya se había previsto con los valores del $R^{2}$ y RCEM que se presentan en la tabla 6.

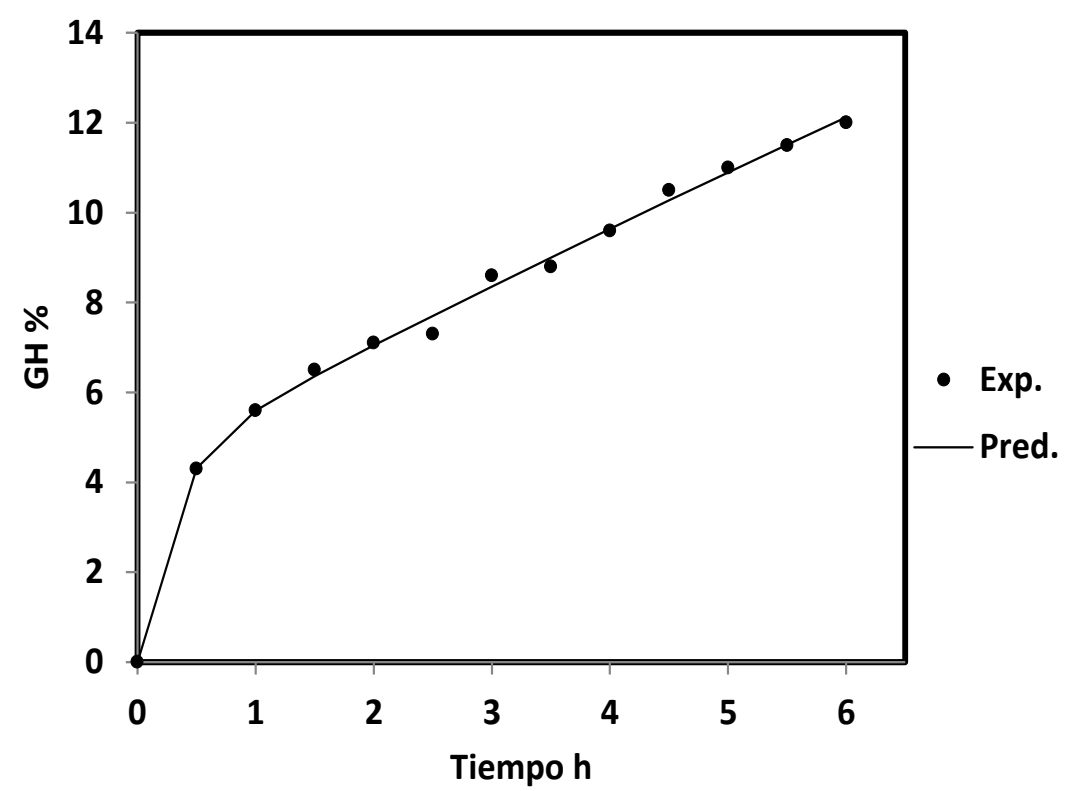

Fig. 2: Comportamiento del $\mathrm{GH}$ con el tiempo a $\mathrm{pH}=9,5$ y $53,45^{\circ} \mathrm{C}$, en la hidrolisis enzimática de vísceras de tilapia roja (Oreochromis spp.) con Alcalasa 2,4L.

\section{Efecto de la concentración de sustrato sobre el GH, en la hidrolisis enzimática de vísceras de tilapia roja}

En la figura 3, se muestran los resultados experimentales para la hidrólisis enzimática en función de la concentración de sustrato. Se observa que a medida que aumenta la concentración de sustrato se reduce el $\mathrm{GH}$ alcanzado. Por otro lado, en cada concentración de sustrato la rapidez de hidrólisis $[\mathrm{d}(\mathrm{GH}) / \mathrm{dt}]$ disminuye en función del tiempo, lo cual se debe generalmente a tres factores (Qi y Hi, 2006; Figueroa et al., 2012): (a) disminución en la concentración de enlaces peptídicos susceptibles a la hidrólisis por las proteasas, (b) posible inhibición de las enzimas causada por el sustrato de hidrólisis; (c) desnaturalización térmica de la enzima. En este caso, el GH tiende hacia valores límites distintos en cada nivel de sustrato evaluado, por lo que es claro que el factor controlante en la velocidad, no es la disminución de enlaces peptídicos 
disponibles. Por otro lado, el fenómeno de desactivación enzimática demostró ser influyente en la disminución de la tasa de hidrólisis para Alcalasa 2,4L, en otros tipos de sustratos (Figueroa et al., 2012).

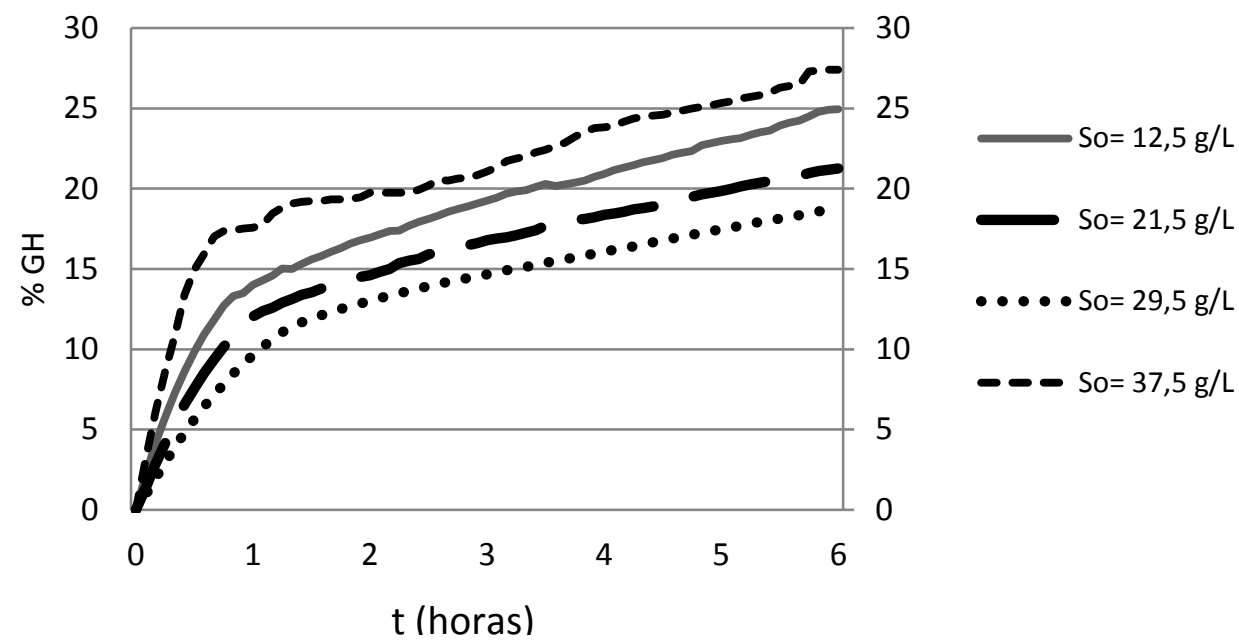

Fig. 3: \%GH vs Tiempo. Comportamiento del GH en función de la concentración de sustrato y el tiempo a $\mathrm{pH}=9,5$ y $53,45^{\circ} \mathrm{C}$, en la hidrolisis enzimática de vísceras de tilapia roja (Oreochromis spp.) con Alcalasa 2.4L.

En la tabla 6 se presentan los valores de la velocidad de reacción en función de la concentración inicial de sustrato para los ensayos desarrollados a $53,45^{\circ} \mathrm{C}, \mathrm{pH} 9,5$ y relación enzima/sustrato 0,2 . Los valores de $r$ fueron calculados a partir del tramo recto inicial, de cada una de las curvas de la figura 3 y se usaron para determinar los parámetros cinéticos de Machaelis-Menten ( $K_{M}$ y $\left.r_{\max }\right)$, a partir de la gráfica de doble reciproco de Hanes-Woolf (Ritchie y Prvan, 1996), que se presenta en la figura 4.

Tabla 7. Velocidad inicial de reacción en función del sustrato a $53,45^{\circ} \mathrm{C}, \mathrm{pH} 9,5$ y relación enzima/sustrato 0,2 , en la hidrolisis enzimática de vísceras de tilapia roja (Oreochromis spp.) con Alcalasa 2,4L.

\begin{tabular}{|c|c|c|}
\hline $\mathrm{S}(\mathrm{g} / \mathrm{L})$ & $\mathrm{r}\left(\mathrm{g} / \mathrm{L}^{*} \min \right)$ & $\mathrm{S} / \mathrm{r}\left(\mathrm{min}^{-1}\right)$ \\
\hline 12,50 & 7,05 & 1,77 \\
\hline 21,25 & 7,21 & 2,95 \\
\hline 29,50 & 7,37 & 4,00 \\
\hline 37,50 & 7,93 & 4,73 \\
\hline
\end{tabular}

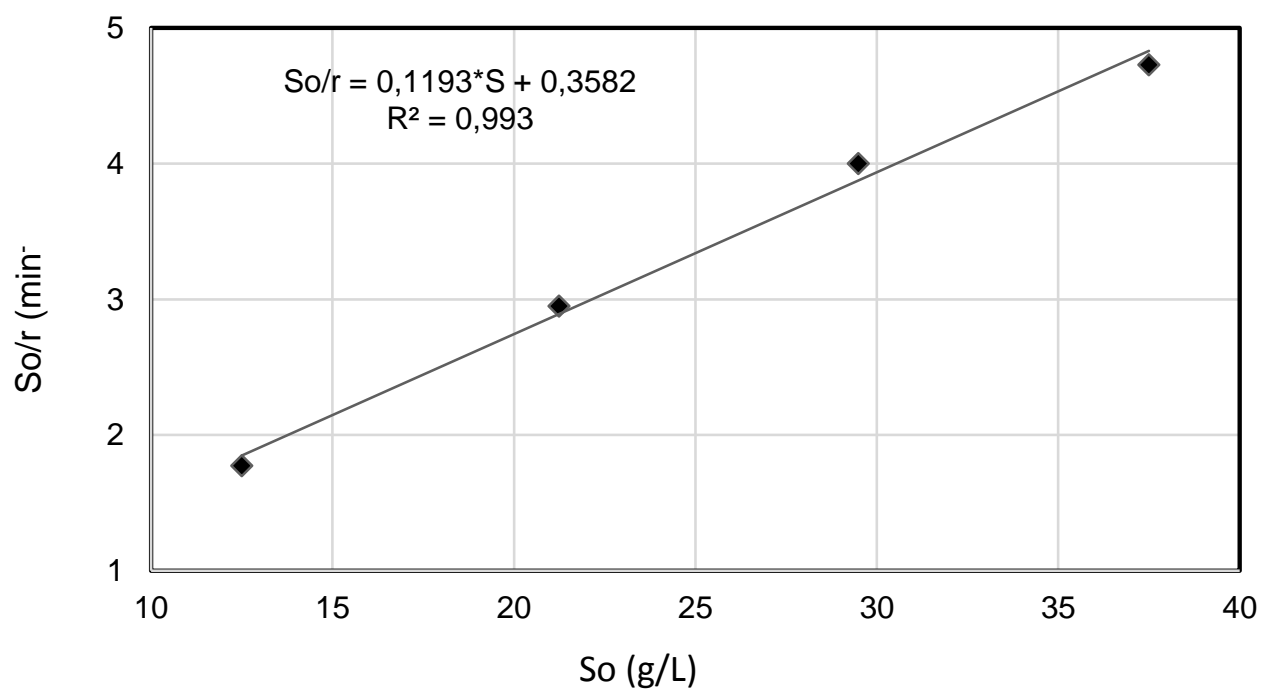

Fig. 4. Representación de Hanes-Woolf para la hidrólisis enzimática de vísceras de tilapia roja (Oreochromis spp.) con Alcalasa 2,4L.

El ajuste de los datos $S$ v.s. S/r, en la figura 4, entregó los valores de $K_{m}=3,00 \mathrm{~g} / \mathrm{L}$ y $\mathrm{r}_{\max }=8,38 \mathrm{~g} / \mathrm{L}^{*} \min$, con un $\mathrm{R}^{2}$ de 0,993 , lo que señala la validez de la transformación doble recíproco de Hanes-Woolf (Ritchie y Prvan, 1996) para representar los datos de este estudio. Este valor de $\mathrm{K}_{\mathrm{m}}$ así como el comportamiento 
gráfico observado en la figura 4, son indicios de que existe baja afinidad de la enzima por el sustrato (Ghassem et al., 2014), posiblemente porque exista algún tipo de efecto negativo del sustrato sobre la actividad de la enzima, que ya ha sido documentado para otros sustratos con esta misma enzima (Figueroa et al., 2016).

\section{Composición química proximal del hidrolizado}

Se tomaron muestras de los ensayos realizados para la maximización del GH con Alcalasa 2,4L, después de 6 horas de reacción, se procedió con la inactivación de la enzima a temperatura de $95{ }^{\circ} \mathrm{C}$ por 15 minutos, esta solución se dejó a $25^{\circ} \mathrm{C}$ durante 20 minutos y se centrifugó para separar las proteínas hidrolizadas (péptidos y aminoácidos) de las partes insolubles; como la grasa, residuos de hueso, tejido conectivo y proteína no hidrolizada. Se observaron cuatro fases diferentes que fueron: aceite, emulsión, sobrenadante (hidrolizado de proteína de pescado) y sedimento en la parte inferior del tubo. El aceite era un líquido amarillo claro. La emulsión una masa aceitosa blanquecina entre el aceite y el sobrenadante. La fracción soluble o el mismo sobrenadante un líquido de color marrón y el lodo que se encontraba en el fondo era de color marrón oscuro con tendencia a negro. Los valores obtenidos en el análisis proximal se muestran en la Tabla 7, en la que cada valor se expresa \pm Desviación estándar. Como puede observarse se obtuvieron valores aceptables de desviación estándar. Se observó que la proteína alcanzó un valor de 6,2\% lo cual es un valor más bajo que el inicial que fue de $8,10 \%$, debido posiblemente a que parte de la proteína en el hidrolizado se quedó en la emulsión formada luego de la centrifugación, lo cual se explica porque en esta fracción hay parte de las proteínas que no se alcanzaron a hidrolizar (Adler-Nissen, 1986). El descenso en el contenido lipídico pudo estar asociado también a la formación de fracciones insolubles removidas en la centrifugación (Hoyle y Merritt, 1994; Shahidi et al., 1994). Esta disminución en contenido graso es favorable para prevenir la rancidez oxidativa de los hidrolizados (Kristinsson y Rasco, 2000).

Tabla 7: Caracterización fisicoquímica del hidrolizado.

Tabla 7: Caracterización fisicoquímica del hidrolizado.
\begin{tabular}{|c|c|c|c|}
\hline Humedad & Grasas & Cenizas & Proteínas \\
\hline $87,84 \pm 0,01$ & $5,91 \pm 0,08$ & $1,09 \pm 0,02$ & $3,10 \pm 0,04$ \\
\hline
\end{tabular}

\section{CONCLUSIONES}

Bajo las condiciones del presente estudio, es posible obtener mayores GH cuando se trabaja con Alcalasa 2,4L que con Neutrasa 1,5MG o Flavourzyme 500MG, en la hidrólisis enzimática de vísceras de Tilapia roja (Oreochromis spp.).

En la hidrólisis de este sustrato con Alcalasa 2,4 L, se tienen efectos significativos de $\mathrm{pH}$ y temperatura, llegando a valores máximos de $\mathrm{GH}$ cuando se trabaja a 53,45ㅇ y pH de 9,5. A estas condiciones el $\mathrm{GH}$ presenta un comportamiento en función del tiempo que puede ser expresado con una ecuación exponencial doble asintótica. Mientras que este mismo parámetro se ve afectado de manera negativa con el incremento de la concentración de sustrato.

La velocidad de la reacción de hidrólisis como función de la concentración de sustrato, se ajusta al modelo doble reciproco de Hanes-Woolf y permite obtener los parámetros de Machaelis-Menten ( $\mathrm{K}_{\mathrm{M}}$ y $\left.\mathrm{r}_{\max }\right)$.

\section{AGRADECIMIENTOS}

Los autores del presente trabajo dan las gracias a la Gobernación de Antioquia, al Sistema General de Regalías de Colombia, al programa ERICA (España y sus Regiones Intercambian conocimiento con Antioquia) y a la estrategia de sostenibilidad 2014-2015 del Comité para el Desarrollo de la Investigación en la Universidad de Antioquia (CODI), por el apoyo financiero entregado.

\section{REFERENCIAS}

Adler-Nissen, J., Enzymic hydrolysis of food proteins. Elsevier Applied Science Publishers, Londres, Inglaterra (1986)

Amiza, M.A., Ashikin S. y Faazaz, A.L., Optimization of enzymatic protein hydrolysis from silver catfish (Pangasius sp.) frame, International Food Research Journal, ISSN: 22317546 (en linea), 18(2): 775-781, (2011), http://www.ifrj.upm.edu.my/18\%20(02)\%202011/(42)\%20IFRJ-2010-098.pdf. Acceso: 15 Junio (2014)

AOAC, 930.15, Official Methods of Analysis of the Association of Official Analytical Chemists, 69, Arlington, USA (1990) 
AOAC, 960.39, Official Methods of Analysis of the Association of Official Analytical Chemists, 931-932, Arlington, USA (1990)

AOAC, 920.153 Official Methods of Analysis of the Association of Official Analytical Chemists, 103-104, Arlington, USA (1990)

AOAC, 954.01, Official Methods of Analysis of the Association of Official Analytical Chemists, 70, Arlington, USA (1990)

Arvanitoyannis, I.S. Potential and Representatives for Application of Environmental Management System (EMS) to Food Industries. doi: 10.1016/B978-012373654-3.50004-3 (2008)

Astiasarán, I., J.A. Martínez, y otros dieciocho autores. Pescados, Alimentos composición y propiedades, $2^{\underline{a}}$ edición, McGraw-Hill-Interamericana, pp 29-52, Madris, España (2000)

Balti, R., Bougatef, A., Sila, A., Guillochon, D., Dhulster, P., y Nedjar-Arroume, N. Nine novel angiotensin Iconverting enzyme (ACE) inhibitory peptides from cuttlefish (Sepia officinalis) muscle protein hydrolysates and antihypertensive effect of the potent active peptide in spontaneously hypertensive rats. doi:10.1016/j.foodchem.2013.03.091. Food Chemistry. 170: 519-525 (2015)

Batista, I., Ramos, C., Coutinho, J., Bandarra, N.M. y Nunes, M.L. Characterization of protein hydrolysates and lipids obtained from black scabbardfish (Aphanopus carbo) by-products and antioxidative activity of the hydrolysates produced, doi:10.1016/j.procbio.2009.07.019, Process Biochemistry 45(1): 18-24 (2010)

Belén Camacho, D. R., Moreno Álvarez, M. J., García, D., Medina, C. y Sidorovas, A. Caracterización de un hidrolizado proteico enzimático obtenido del pez caribe colorado (Pygocentrus cariba Humboldt, 1821). Interciencia, 32(3), 188-193 (2007)

Bhaskar, N., Benila, T., Radha, C. y Lalitha, R.G., Optimization of enzymatic hydrolysis of visceral waste proteins of Catla (Catla catla) for preparing protein hydrolysate using a commercial protease, doi:10.1016/j.biortech.2006.12.015, Bioresource Technology. (en línea) 99(2): 335-343 (2008)

Bhaskar, N. y Mahendrakar, N.S., Protein hydrolysate from visceral waste proteins of Catla (Catla catla): Optimization of hydrolysis conditions for a commercial neutral protease, doi: 10.1016/j.biortech.2007.09.006, Bioresource Technol. (en línea), 99(10), 4105-4111 (2008)

Bourseau, P., Vandanjon, L., y otros dieciséis autores, Fractionation of fish protein hydrolysates by ultrafiltration and nanofiltration: impact on peptidic populations. doi:10.1016/j.desal.2008.05.026. Desalination, 244 (1-2): 303-320 (2009)

Chalamaiah, M., Dinesh Kumar, B., Hemalatha, R. y Jyothirmayi, T., Fish protein hydrolysates: Proximate composition, amino acid composition, antioxidant activities and applications: A review. doi:10.1016/j.foodchem.2012.06.100. Food Chemistry, 135 (4): 3020-3038 (2012)

De Castro, R. J. S. y Sato, H.H., Biologically active peptides: Processes for their generation, purification and identification and applications as natural additives in the food and pharmaceutical industries. doi:10.1016/j.foodres.2015.05.013. Food Research International, 74: 185-198 (2015)

Deraz, S. F., Protein Hydrolysate from Visceral Waste Proteins of Bolti Fish (Tilapia nilotica): Chemical and Nutritional Variations as Affected by Processing $\mathrm{pHs}$ and Time of Hydrolysis. doi: 10.1080/10498850.2013.797534. Journal of Aquatic Food Product Technology. (en línea), 24(6), 614-631 (2014)

Dekkers, E., Raghavan S., Kristinsson H.G. y Marshall M.R., Oxidative stability of mahi mahi red muscle dipped in tilapia protein hydrolysates, doi: 10.1016/j.foodchem.2010.06.088, Food Chem. (en línea), 124(2), 640-645 (2011)

Dong, Y.L., Sheng G.Y., Fu J.M. y Wen K.W., Chemical characterization and anti-anaemia activity of fish protein hydrolysate from Saurida elongata, doi: 10.1002/jsfa.2219, J Sci Food Agr, (en línea), 85(12), 20332039 (2005) 
Duan, Z.H., Wang, J.L., Yi, M.H. y Yin, A.Q., Recovery of proteins from silver carp by products with enzymatic hydrolysis and reduction of bitterness in hydrolysate, doi: 10.1111/j.1745-4530.2008.00318.x, J Food Process Eng, (en línea), 33(5), 962-978 (2010)

Dumay, J., Donnay, C., Barnathan, G., Jaouen, P. y Bergé J.P., Improvement of lipid and phospholipid recoveries from sardine (Sardina pilchardus) viscera using industrial proteases, doi: 10.1016/j.procbio.2006.04.005, Process Biochem, (en línea), 41(11), 2327-2332 (2006)

Figueroa, O.A., J. E. Zapata y G.A. Gutierrez, Modelamiento de la Cinética de Hidrólisis Enzimática de Proteínas de Plasma Bovino, Rev. EIA, 9(17), 71-84, (2012)

Figueroa, O.A., Zapata, J.E. y Sánchez, C.P., Efectos del pH, la Temperatura y Relación de Enzima Sustrato en la Hidrólisis Enzimática de Proteínas de Plasma Bovino, Inf. Tecnol. 27(2), en prensa (2016)

Gbogouri, G.A., Linder, M., Fanni, J. y Parmentier, M., Influence of hydrolysis degree on the functional properties of salmon byproduct hydrolysates, doi: 10.1111/j.1365-2621.2004.tb09909.x, Journal of Food Science 69(8): 615-622 (2004)

Ghaly A.E., RamakrishnaN, V.V., Brooks, M.S., Budge S.M \& Dave, D., Fish Processing Wastes as a Potential Source of Proteins, Amino Acids and Oils: A Critical Review, J Microb Biochem Technol, ISSN: 1948-5948, 5(4): 107-129. http://dx.doi.org/10.4172/1948-5948.1000110. (2013)

Ghassem, M., Fern, S., Said, M., Ali, Z., Ibrahim, S., Babji, A.S., Kinetic characterization of Channa striatus muscle sarcoplasmic and myofibrillar protein hydrolysates, doi: 10.1007/s13197-011-0526-6, J Food Sci Technol 51(3):467-475 (2014)

Gómez, L. J., Figueroa, O. y Zapata, J.E., Actividad Antioxidante de Hidrolizados Enzimáticos de Plasma Bovino Obtenidos por Efecto de Alcalasa® 2.4 L, doi: 10.4067/S0718-07642013000100005, Información Tecnológica (en línea), 24(1): 33-42 (2013)

Guadix, A., F. Camacho, V. Bravo y A. Guadix, Producción en reactores de membrana de hidrolizados enzimáticos de proteínas lácteas para nutrición enteral, Tesis de Doctorado, Universidad de Granada, Facultad de Ciencias (2002)

He, S., Franco, C. y Zhang, W., Functions, applications and production of protein hydrolysates from fish processing co-products (FPCP). doi:10.1016/j.foodres.2012.10.031. Food Research International. (en línea), 50(1), 289-297 (2013)

He, S., Wang, F., Ning, Z., Yang, B. y Wang Y., Preparation of anchovy (Engraulis japonicus) protein hydrolysates with high free radical-scavenging activity using endogenous and commercial enzymes, doi: 10.1177/1082013213496418, Food. Sci. Technol. (en línea), 20(8): 567-78, (2014)

Hoyle, N.T., y Merritt, J.H., Quality of Fish Protein Hydrolysates from Herring (Clupea harengus, doi: 10.1111/j.1365-2621.1994.tb06901.x, J Food SCI, (en línea), 59(1), 76-79 (1994)

Hsu, K.C., Purification of antioxidative peptides prepared from enzymatic hydrolysates of tuna dark muscle by-product, doi: 10.1016/j.foodchem.2010.02.013, Food Chem, (en línea), 122(1), 42-48 (2010)

Kechaou, E., Dumay, J., Donnay, C., Jaouen, P.I., Gouygou, J.P., Bergé \& J.P. Amar, R.B., Enzymatic hydrolysis of cuttlefish (Sepia officinalis) and sardine (Sardina pilchardus) viscera using commercial proteases: Effects on lipid distribution and amino acid composition, doi: 10.1016/j.jbiosc.2008.10.018, Journal of Bioscience and Bioengineering 107 (2):158-164, (2009)

Klompong, V., Benjakul, S., Kantachote, D. y Shahidi, F., Antioxidative activity and functional properties of protein hydrolysate of yellow stripe trevally (Selaroides leptolepis) as influenced by the degree of hydrolysis and enzyme type, doi: 10.1016/j.foodchem.2006.07.016, Food Chem, (en línea), 102(4), 1317-1327 (2007)

Kristinsson, HG.y B.A. Rasco, Fish Protein Hydrolysates: Production, Biochemical, and Functional Properties, Crit Rev Food SCI, 40(1), 43-81 (2000)

Lee, S.H., Qian, Z.J. y Kim, S.K., A novel angiotensin I converting enzyme inhibitory peptide from tuna frame protein hydrolysate and its antihypertensive effect in spontaneously hypertensive rats, doi:10.1016/j.foodchem.2009.04.086, Food Chemistry. (en línea) 118(1), 96-102 (2010) 
Liu, Y., L. Xianghong y otros cuatro autores, Characterization of structural and functional properties of fish protein hydrolysates from surimi processing by-products, doi:10.1016/j.foodchem.2013.11.089, Food Chemistry. (en línea) 151(15), 459-465 (2014)

Martínez-Alvarez, O., Chamorro, S. y Brenes, A., Protein hydrolysates from animal processing by-products as a source of bioactive molecules with interest in animal feeding: $A$ review, doi:10.1016/j.foodres.2015.04.005, Food Research International. (en línea), 73, 204-212 (2015)

Opheim, M., R. Šližytèb y otros cuatro autores, Hydrolysis of Atlantic salmon (Salmo salar) rest raw materials-Effect of raw material and processing on composition, nutritional value, and potential bioactive peptides in the hydrolysates, doi:10.1016/j.procbio.2015.04.017, Process Biochemistry. (en línea), 50(8), 1247-1257 (2015)

Ovissipour, M., A. Abedian y otros cinco autores, The effect of enzymatic hydrolysis time and temperature on the properties of protein hydrolysates from Persian sturgeon (Acipenser persicus) viscera, doi:10.1016/j.foodchem.2008.12.013, Food Chemistry. (en línea), 115(1), 238-242 (2009)

Pérez-Gálvez R., M.C. Almécija y otros tres autores, Bi-objective optimisation of the enzymatic hydrolysis of porcine blood protein, doi: 10.1016/j.bej.2010.12.004, Biochem Eng J. (en línea), 53(3), 305-10 (2011)

Picot, L., R. Ravallec y otros diecisiete autores, Impact of ultrafiltration and nanofiltration of an industrial fish protein hydrolysate on its bioactive properties, doi:10.1002/jsfa.4020, J. Sci. Food. Agric. (en línea), 90(11), 1819-1826 (2010)

Prieto C. A., E. M Guadix y A Guadix., Influence of temperature on protein hydrolysis in a cyclic batch enzyme membrane reactor, Biochem Eng J., (en línea), 42(3), 217-23 (2008)

Qi, W. y He, Z., Enzymatic hydrolysis of protein: Mechanism and kinetic model. doi:10.1007/s114458-0060026-9, Frontiers of Chemistry in China. (en línea), 3, 308-314 (2006)

Ren, J., Zhao, M., Shi, J., Wang, J., Jiang, Y., Cui, C., Kakuda, Y. y Xue, S.J., Purification and identification of antioxidant peptides from grass carp muscle hydrolysates by consecutive chromatography and electrospray ionization-mass spectrometry, doi: 10.1016/j.foodchem.2007.11.010 Food Chem, (en línea), 108(2), 727-736, (2008)

Ritchie, R.J. y Prvan, T., Current Statistical Methods for Estimating the $\mathrm{Km}$ and Vmax of Michaelis-Menten Kinetics, doi: 10.1016/S0307-4412(96)00089-1, Biochemical Education. (en línea), 24(4): 196-206 (1996)

Rodríguez, J.C., A.M. Cabello, B. Figuera, M. Ramosy O. Vallenilla., Caracterización y aprovechamiento de la pulpa del caribe colorado (pigocentrus cariba humboldt 1821) para la elaboración de productos alimenticios Interciencia 26(4), 161-165 (2001)

Roslan, J., S.M. Mustapa y otros tres autores, Optimization of Enzymatic Hydrolysis of Tilapia Muscle (Oreochromis niloticus) using Response Surface Methodology (RSM). Sains Malaysiana, 43(11), 1715-1723 (2014)

Saidi, S., Deratani, A., Ben Amar, R. y Belleville, M.P., Fractionation of a tuna dark muscle hydrolysate by a two-step membrane process. doi:10.1016/j.seppur.2013.01.048, Separation and Purification Technology. (en línea), 108, 28-36 (2013)

Saidi, S., Deratani, A., Belleville, M.P. y Amar, R.B., Production and fractionation of tuna by-product protein hydrolysate by ultrafiltration and nanofiltration: Impact on interesting peptides fractions and nutritional properties, doi:10.1016/j.foodres.2014.04.026, Food Research International. (en línea), 65(Part C) 453-461 (2014)

Saadi, S., Saari, N., Anwar, F., Abdul Hamid, A. y Ghazali, H.M., Recent advances in food biopeptides: Production, biological functionalities and therapeutic applications, doi:10.1016/j.biotechadv.2014.12.003, Biotechnology Advances. (en línea), 33(1), 80-116 (2015)

See, S.F., Hoo, L.L. y Babji, A.S., Optimization of enzymatic hydrolysis of Salmon (Salmo salar) skin by Alcalase, International Food Research Journal, ISSN: 22317546 (en linea), 18(4): 1359-1365, 2011, http://www.ifrj.upm.edu.my/18\%20(04)\%202011/(22)IFRJ-2011-267.pdf. Acceso: 18 Mayo (2016) 
Shahidi, F. y Ambigaipalan, P., Novel Functional Food Ingredients from Marine Sources, doi:10.1016/j.cofs.2014.12.009, Current Opinion in Food Science. (en línea), 2, 123-129 (2015)

Shahidi, F., Synowiecki, J. y Balejko, J., Proteolytic hydrolysis of muscle proteins of Harp Seal (Phoca groenlandica), doi: 10.1021/jf00047a048, J. Agric. Food Chem 42(11), 2634-2638 (1994)

Shahidi, F., Vidana, J.K. y Jeon, Y.J., Food applications of chitin and chitosans, doi:10.1016/S09242244(99)00017-5, Trends Food Sci Tech, (en línea), 10(2), 37-51 (1999)

Shetty, K., G. Paliyath, A. Pometto y R.E. Levin, Food biotechnology, 2da edición. Taylor and Francias Group, Londres, Inglaterra (2006)

Shi, D., He, Z. y Qi, W., Lumping kinetic study on the process of tryptic hydrolysis of bovine serum albumin, doi:10.1016/j.procbio.2004.07.009, Process Biochem, (en línea), 40(5), 1943-1949, (2005)

Sikorski, Z.E., B.S. Pan, y F. Shahidi., Seafood Proteins. Chapman \& Hall, Nueva York, EUA (1994)

Silva, J.F.X., Ribeiro, K., Silva, J.F., Cahú, T.B. y Bezerra, R.S. , Utilization of tilapia processing waste for the production of fish protein hydrolysate, doi: http://dx.doi.org/10.1016/j.anifeedsci.2014.06.010, Animal Feed Science and Technology. (en línea) 196: 96-106 (2014)

Slizyte, R., Dauksas, E., Falch, E., Storrøa, I. y Rusta, T., Characteristics of protein fractions generated from hydrolysed cod (Gadus morhua) by-products, doi:10.1016/j.procbio.2004.07.016, Process Biochemistry. (en línea), 40(6): 2021-2033 (2005)

Souissi, N., Bougatef, A., Triki-Ellouz, Y., y Nasri, M., Biochemical and functional properties of Sardinelle (Sardinella aurita) by-product hydrolysates, Food Technology and Biotechnology, ISSN: 1330-9862 (PDF), 45(2): 187-194 (2007). hrcak.srce.hr/file/43776 (2007)

Valencia, P., Pinto, M. y Almonacid, S., Identification of the key mechanisms involved in the hydrolysis of fish protein by Alcalase, doi:10.1016/j.procbio.2013.11.012, Process Biochemistry. (en línea), 49(2), 258-264 (2014)

Wang, B., Li, L., Chi, C.F., Ma, J.H., Luo, H.Y. y Xu, Y.F., Purification and characterisation of a novel antioxidant peptide derived from blue mussel (Mytilus edulis) protein hydrolysate, doi:10.1016/j.foodchem.2012.12.002, Food Chemistry. (en línea), 138(2-3), 1713-1719 (2013)

ZunZun. "ZunZun Online Curve Fitting and Suface Fitting Web Site", 2012. http://www.zunzun.com. Acceso: Junio 15 (2014) 